\title{
Benchmark Database of Barrier Heights for Heavy Atom Transfer, Nucleophilic Substitution, Association, and Unimolecular Reactions and Its Use to Test Theoretical Methods
}

\author{
Yan Zhao, Núria González-García, and Donald G. Truhlar* \\ Department of Chemistry and Supercomputing Institute, University of Minnesota, \\ Minneapolis, Minnesota 55455-0431
}

Received: October 25, 2004; In Final Form: December 8, 2004

\begin{abstract}
A benchmark database of forward and reverse barrier heights for 19 non-hydrogen-transfer reactions has been developed by using Weizmann 1 calculations, and 29 DFT methods and 6 ab initio wave-function theory (WFT) methods have been tested against the new database as well as against an older database for hydrogen atom transfer reactions. Among the tested hybrid DFT methods without kinetic energy density, MPW $1 \mathrm{~K}$ is the most accurate model for calculations of barrier heights. Among the tested hybrid meta DFT methods, $\mathrm{BB} 1 \mathrm{~K}$ and MPWB1K are the two most accurate models for the calculations of barrier heights. Overall, the results show that BB1K and MPWB1K are the two best DFT methods for calculating barrier heights, followed in order by MPW1K, MPWKCIS1K, B1B95, MPW1B95, BHandHLYP, B97-2, mPW1PW91, and B98. The popular B3LYP method has a mean unsigned error four times larger than that of BB1K. Of the methods tested, QCISD(T) is the best ab initio WFT method for barrier height calculations, and QCISD is second best, but QCISD is outperformed by the BB1K, MPWB1K, MPWKCIS1K, and MPW1K methods.
\end{abstract}

\section{Introduction}

Density-functional theory (DFT) methods $^{1-59}$ have been shown to be more efficient than wave-function theory (WFT) methods for computational thermochemistry and thermochemical kinetics due to their excellent cost-to-performance ratio. However pure DFT methods overestimate bond energies and underestimate barrier heights (BHs) for chemical reactions. One of the practical ways to tackle this problem is to use hybrid DFT $^{11}$ (mixing Hartree-Fock (HF) theory with Kohn-Sham DFT at the level of the Fock-Kohn-Sham operator). Hybrid DFT methods can be justified theoretically by the adiabatic connection theorem (ACT). ${ }^{56}$ Nevertheless the most popular hybrid DFT method, B3LYP, 6,11,12 is only parametrized against a data set for thermochemistry, and it significantly underestimates BHs. The first successful hybrid DFT model for thermochemical kinetics was MPW1K. ${ }^{30}$ It was parametrized against a database of $44 \mathrm{BHs}$ of 22 reactions, 21 of which are hydrogentransfer (HT) reactions. This database of $\mathrm{BHs}$ was updated later as $\mathrm{BH} 44 / 3$ (one part of Database/3), ${ }^{42,57} \mathrm{BH} 42 / 04,{ }^{50,53,58}$ and HTBH38/04 ${ }^{59}$ by taking into account some new experimental and theoretical results in the literature and by leaving out data that are not reliable or that are not for HT reactions. This database was successfully employed in conjunction with other databases to parametrize or test some new methods such as multicoefficient correlation methods (MCCM/3), ${ }^{57}$ hybrid meta DFT methods (BB1K, ${ }^{50} \mathrm{MPWB} 1 \mathrm{~K},{ }^{53}$ and TPSS1KCIS, ${ }^{59}$ where "meta" means that the hybrid density functional also depends on the Kohn-Sham orbitals in the form of a kinetic energy density), and multi-coefficient extrapolated DFT methods (MC3BB, ${ }^{58}$ MC3MPW, ${ }^{58}$ and a suite of methods in a previous paper ${ }^{59}$ ). Since this database mainly consists of $\mathrm{BHs}$ for $\mathrm{HT}$ reactions, and in its current form, HTBH38/04, it contains only HT BHs, one of the goals of the present paper is to develop a database of BHs for non-HT reactions, and we will employ this new database to assess some hybrid and hybrid meta DFT methods.

A brief comment on notation is useful here. Both "KohnSham DFT" and "hybrid DFT" are legitimate forms of DFT because the "Hartree-Fock exchange" (also called "exact exchange") included in hybrid DFT is computed from orbitals that are functionals of the density. The "pure" (or "KohnSham") density functionals depend both directly on the density (first rung of "Jacob's ladder"46) and on the gradient magnitude (so-called generalized gradient approximation or GGA). The meta functionals depend on kinetic energy density, which is computed from orbitals that are functionals of the density, so meta DFT is also a legitimate form of DFT. The present article does not consider density functionals with more complicated dependencies on the density or orbitals. Thus the methods considered here differ in the choice of GGA, in the way that kinetic energy density is or is not included, and in the fraction of Hartree-Fock exchange. We sometimes distinguish pure DFT, meta DFT, hybrid DFT, and hybrid Meta DFT, but we could equally well just call each of these DFT.

Section 2 explains the theories, databases, and functionals used in the present work. Section 3 presents results and discussion, and section 4 has concluding remarks.

\section{Theory and Databases}

2.1. Weizmann-1 (W1) Theory. Whereas the HTBH database is primarily built on theoretically corrected experimental data, we used a different approach in the present study. In particular, to obtain the best estimates for the BHs in the new database, we employed the W1 method for most reactions. This method was developed by Martin and Oliveira, and it is a method designed to extrapolate to the complete basis limit of a $\operatorname{CCSD}(\mathrm{T})^{60}$ calculation. Note that $\mathrm{W} 1$ results are not "exact",

\subsection{1/jp045141s CCC: $\$ 30.25$ (C) 2005 American Chemical Society}

Published on Web 02/09/2005 
TABLE 1: Components of W1 Calculations for BHs (kcal/mol)

\begin{tabular}{|c|c|c|c|c|c|c|c|}
\hline reaction & barrier $^{a}$ & SCF limit & CCSD limit & (T) limit & core correlation and relativistic & $\mathrm{S}-\mathrm{O}$ coupling & final $\mathrm{BH}$ \\
\hline \multirow[t]{2}{*}{$\mathrm{H} \cdot+\mathrm{N}_{2} \mathrm{O} \rightarrow \mathrm{OH} \cdot+\mathrm{N}_{2}$} & $\mathrm{~V}_{\mathrm{f}} \neq$ & 27.79 & -9.25 & -0.50 & 0.10 & 0.00 & 18.14 \\
\hline & $\mathrm{V}_{\mathrm{r}}^{\neq}$ & 124.05 & -32.64 & -7.96 & -0.03 & -0.20 & 83.22 \\
\hline \multirow[t]{2}{*}{$\mathrm{H}+\mathrm{FH} \rightarrow \mathrm{HF}+\mathrm{H}$} & $V_{f}^{\neq}$ & 57.72 & -14.02 & -1.48 & -0.05 & 0.00 & 42.18 \\
\hline & $\mathrm{V}_{\mathrm{r}}^{\neq}$ & 57.72 & -14.02 & -1.48 & -0.05 & 0.00 & 42.18 \\
\hline \multirow[t]{2}{*}{$\mathrm{H}+\mathrm{FCH}_{3} \rightarrow \mathrm{HF}+\mathrm{CH}_{3}$} & $\mathrm{~V}_{\mathrm{f}}^{\neq}$ & 47.16 & -14.72 & -2.07 & 0.01 & 0.00 & 30.38 \\
\hline & $V_{r}^{*}$ & 73.66 & -13.36 & -3.34 & 0.07 & 0.00 & 57.02 \\
\hline \multirow[t]{2}{*}{$\mathrm{H}+\mathrm{F}_{2} \rightarrow \mathrm{HF}+\mathrm{F}$} & $V_{f}^{*}$ & -9.54 & 12.18 & -0.41 & 0.04 & 0.00 & 2.27 \\
\hline & $V_{r}^{*}$ & 123.35 & -12.04 & -5.56 & 0.05 & 0.38 & 106.18 \\
\hline \multirow{2}{*}{$\mathrm{CH}_{3}+\mathrm{FCl} \rightarrow \mathrm{CH}_{3} \mathrm{~F}+\mathrm{Cl}$} & $V_{f}^{*}$ & 16.74 & -6.65 & -2.71 & 0.05 & 0.00 & 7.43 \\
\hline & $\mathrm{V}_{\mathrm{r}}^{\neq}$ & 78.49 & -13.79 & -4.54 & 0.00 & 0.84 & 60.17 \\
\hline \multirow[t]{2}{*}{$\mathrm{OH}^{-}+\mathrm{CH}_{3} \mathrm{~F} \rightarrow \mathrm{HOCH}_{3}+\mathrm{F}^{-}$} & $\mathrm{V}_{\mathrm{f}}^{\neq}$ & 7.70 & -7.64 & -2.84 & 0.01 & 0.00 & -2.78 \\
\hline & $\mathrm{V}_{\mathrm{r}}^{\neq}$ & 28.64 & -8.14 & -3.17 & 0.24 & 0.00 & 17.33 \\
\hline \multirow[t]{2}{*}{$\mathrm{OH}^{-} \cdots \mathrm{CH}_{3} \mathrm{~F} \rightarrow \mathrm{HOCH}_{3} \cdots \mathrm{F}^{-b}$} & $V_{\mathrm{f}}^{\neq}$ & 19.07 & -5.66 & -2.46 & 0.15 & 0.00 & 10.96 \\
\hline & $\mathrm{V}_{\mathrm{r}}^{\neq}$ & 53.70 & -4.06 & -2.43 & 0.26 & 0.00 & 47.20 \\
\hline \multirow[t]{2}{*}{$\mathrm{H}+\mathrm{N}_{2} \rightarrow \mathrm{HN}_{2}$} & $V_{f}^{\neq}$ & 22.91 & -7.77 & -0.55 & 0.10 & 0.00 & 14.69 \\
\hline & $\mathrm{V}_{\mathrm{r}}^{\neq}$ & 13.55 & -1.88 & -0.92 & -0.03 & 0.00 & 10.72 \\
\hline \multirow[t]{2}{*}{$\mathrm{H}+\mathrm{CO} \rightarrow \mathrm{HCO}$} & $V_{f}^{*}$ & 9.05 & -5.35 & -0.54 & 0.02 & 0.00 & 3.17 \\
\hline & $V_{r}^{*}$ & 17.31 & 5.65 & -0.40 & 0.13 & 0.00 & 22.68 \\
\hline \multirow[t]{2}{*}{$\mathrm{H}+\mathrm{C}_{2} \mathrm{H}_{4} \rightarrow \mathrm{CH}_{3} \mathrm{CH}_{2}$} & $\mathrm{~V}_{\mathrm{f}}^{\neq}$ & 9.67 & -7.13 & -0.55 & 0.05 & 0.00 & 2.05 \\
\hline & $V_{r}^{*}$ & 46.79 & -2.22 & -2.45 & -0.04 & 0.00 & 42.08 \\
\hline \multirow[t]{2}{*}{$\mathrm{CH}_{3}+\mathrm{C}_{2} \mathrm{H}_{4} \rightarrow \mathrm{CH}_{3} \mathrm{CH}_{2} \mathrm{CH}_{2}$} & $V_{f}^{\neq}$ & 23.54 & -14.94 & -2.07 & 0.32 & 0.00 & 6.85 \\
\hline & $V_{r}^{*}$ & 41.36 & -6.36 & -2.14 & 0.11 & 0.00 & 32.97 \\
\hline \multirow{2}{*}{$\mathrm{HCN} \rightarrow \mathrm{HNC}$} & $V_{\mathrm{f}}^{\neq}$ & 47.38 & 0.86 & -0.41 & 0.33 & 0.00 & 48.16 \\
\hline & $\mathrm{V}_{\mathrm{r}}^{\neq}$ & 37.65 & -3.82 & -0.80 & 0.08 & 0.00 & 33.11 \\
\hline
\end{tabular}

${ }^{a} \mathrm{~V}_{\mathrm{f}} \neq$ denotes forward $\mathrm{BH}$, and $\mathrm{V}_{\mathrm{r}}{ }^{\neq}$denotes reverse BH. ${ }^{b}$ This denotes the reaction between the reactant complex and product complex for the previous $\mathrm{S}_{\mathrm{N}} 2$ reaction.

but all experience in the literature is consistent with the fact that the complete basis set limit of $\operatorname{CCSD}(\mathrm{T})$ should be accurate to better than $1 \mathrm{kcal} / \mathrm{mol}$ for the $\mathrm{BHs}$ of most reactions. Thus W1 theory should be good enough for testing any methods whose errors exceed this. Recently Coote ${ }^{61}$ used the W1 model to obtain reference data for some hydrogen abstraction reactions. Boese and Martin ${ }^{55}$ also used W1 and W2 theory to calculate best estimates for some reactions. The strength and limitations of W1 theory have been described elsewhere. ${ }^{62-66}$ It is hard to imagine any other way to get results of benchmark accuracy for most of the reactions studied here; extracting the $\mathrm{BH}$ from experiment is usually not sufficient for the required accuracy because of uncertainties in the experimental results and because of the difficulty of inverting the experimental data to obtain a classical $\mathrm{BH}$, which cannot be directly observed.

2.2. Benchmark Database of BHs for Non-HT Reactions. The new database consists of forward and reverse BHs for 19 reactions, which consist of 6 heavy-atom transfer reactions, 4 bimolecular nucleophilic substitution $\left(\mathrm{S}_{\mathrm{N}} 2\right)$ reactions, 4 unimolecular nucleophilic substitution reactions for reactions of the reactant complex and product complex for the $4 \mathrm{~S}_{\mathrm{N}} 2$ reactions, and 5 association or non-nucleophilic-substitution unimolecular reactions. The best estimates of the BHs of three of the four $\mathrm{S}_{\mathrm{N}} 2$ reactions are taken from Parthiban et al.; ${ }^{63}$ two of these are based on $\mathrm{W} 2^{62}$ calculations, and we obtain $3.10 \mathrm{kcal} / \mathrm{mol}$ for the forward and reverse $\mathrm{BHs}$ for the reaction $\mathrm{Cl}^{-}+\mathrm{CH}_{3} \mathrm{Cl}$ $\rightarrow \mathrm{ClCH}_{3}+\mathrm{Cl}^{-}$by a semiempirical adjustment to experiment. ${ }^{67}$ The fourth reaction, $\mathrm{OH}^{-}+\mathrm{CH}_{3} \mathrm{~F}$, is based on $\mathrm{W} 1$ calculations performed in the present study. The best estimates for the forward and reverse $\mathrm{BHs}$ of one of the heavy-atom transfer reactions, namely, $\mathrm{H}+\mathrm{ClH} \rightarrow \mathrm{HCl}+\mathrm{H}$, are taken from the BH42/04 database. ${ }^{50,53,58}$ The forward $\mathrm{BH}$ of the reaction $\mathrm{H}+$ $\mathrm{C}_{2} \mathrm{H}_{4}$ is taken from a dynamics study, ${ }^{68}$ and the reverse reaction $\mathrm{BH}$ is calculated by using the energy of reaction obtained by $\mathrm{W} 1$ and the forward $\mathrm{BH}$. The best estimates for the rest of the reactions are obtained by $\mathrm{W} 1$ calculations. The results of the W1 calculations are summarized in Table 1, and the new database is described in Table 2.

2.3. HTBH38/04 Database. The HTBH38/04 database is taken from a previous paper. ${ }^{59}$ It consists of 38 transition-state
TABLE 2: Benchmark Database of BHs for Non-HT Reactions $^{a}$

\begin{tabular}{|c|c|c|c|}
\hline reactions & barrier $^{a}$ & $\begin{array}{l}\text { best estimate } \\
(\mathrm{kcal} / \mathrm{mol})\end{array}$ & ref \\
\hline \multicolumn{4}{|c|}{ Heavy-Atom Transfer Reactions } \\
\hline \multirow{2}{*}{$\mathrm{H}+\mathrm{N}_{2} \mathrm{O} \rightarrow \mathrm{OH}+\mathrm{N}_{2}$} & $\mathrm{~V}_{\mathrm{f}}^{\neq}$ & 18.14 & this work \\
\hline & $V_{r}{ }^{7}$ & 83.22 & this work \\
\hline \multirow{2}{*}{$\mathrm{H}+\mathrm{FH} \rightarrow \mathrm{HF}+\mathrm{H}$} & $V_{f}^{\neq}$ & 42.18 & this work \\
\hline & $\mathrm{V}_{\mathrm{r}}^{\neq}$ & 42.18 & this work \\
\hline \multirow{2}{*}{$\mathrm{H}+\mathrm{ClH} \rightarrow \mathrm{HCl}+\mathrm{H}$} & $V_{\mathrm{f}}^{\neq}$ & 18.00 & 30,34 \\
\hline & $\mathrm{V}_{\mathrm{r}}^{\neq}$ & 18.00 & 30,34 \\
\hline \multirow{2}{*}{$\mathrm{H}+\mathrm{FCH}_{3} \rightarrow \mathrm{HF}+\mathrm{CH}_{3}$} & $V_{f}^{f}$ & 30.38 & this work \\
\hline & $V_{r}^{*}$ & 57.02 & this work \\
\hline \multirow{2}{*}{$\mathrm{H}+\mathrm{F}_{2} \rightarrow \mathrm{HF}+\mathrm{F}$} & $V_{f}^{\neq}$ & 2.27 & this work \\
\hline & $\mathrm{V}_{\mathrm{r}}^{\neq}$ & 106.18 & this work \\
\hline \multirow[t]{2}{*}{$\mathrm{CH}_{3}+\mathrm{FCl} \rightarrow \mathrm{CH}_{3} \mathrm{~F}+\mathrm{Cl}$} & $\mathrm{V}_{\mathrm{f}}^{\neq}$ & 7.43 & this work \\
\hline & $\mathrm{V}_{\mathrm{r}}^{\neq}$ & 60.17 & this work \\
\hline \multicolumn{4}{|c|}{ Nucleophilic Substitution Reactions } \\
\hline \multirow{2}{*}{$\mathrm{F}^{-}+\mathrm{CH}_{3} \mathrm{~F} \rightarrow \mathrm{FCH}_{3}+\mathrm{F}^{-}$} & $\mathrm{V}_{\mathrm{f}}^{\neq}$ & -0.34 & 63 \\
\hline & $\mathrm{V}_{\mathrm{r}}^{\neq}$ & -0.34 & 63 \\
\hline \multirow[t]{2}{*}{$\mathrm{F}^{-} \cdots \mathrm{CH}_{3} \mathrm{~F} \rightarrow \mathrm{FCH}_{3} \cdots \mathrm{F}^{-}$} & $\mathrm{V}_{\mathrm{f}}^{\neq}$ & 13.38 & 63 \\
\hline & $V_{r}^{7}$ & 13.38 & 63 \\
\hline \multirow{2}{*}{$\mathrm{Cl}^{-}+\mathrm{CH}_{3} \mathrm{Cl} \rightarrow \mathrm{ClCH}_{3}+\mathrm{Cl}^{-}$} & $\mathrm{V}_{\mathrm{f}}^{\neq}$ & 3.10 & 67 \\
\hline & $\mathrm{V}_{\mathrm{r}}^{\neq}$ & 3.10 & 67 \\
\hline \multirow[t]{2}{*}{$\mathrm{Cl}^{-} \cdots \mathrm{CH}_{3} \mathrm{Cl} \rightarrow \mathrm{ClCH}_{3} \cdots \mathrm{Cl}^{-}$} & $\mathrm{V}_{\mathrm{f}}^{\neq}$ & 13.61 & 63 \\
\hline & $V_{r}{ }^{7}$ & 13.61 & 63 \\
\hline \multirow[t]{2}{*}{$\mathrm{F}^{-}+\mathrm{CH}_{3} \mathrm{Cl} \rightarrow \mathrm{FCH}_{3}+\mathrm{Cl}^{-}$} & $V_{f}^{\neq}$ & -12.54 & 63 \\
\hline & $V_{r}{ }^{7}$ & 20.11 & 63 \\
\hline \multirow{2}{*}{$\mathrm{F}^{-} \cdots \mathrm{CH}_{3} \mathrm{Cl} \rightarrow \mathrm{FCH}_{3} \cdots \mathrm{Cl}^{-}$} & $V_{f}^{f}$ & 2.89 & 63 \\
\hline & $V_{r}{ }^{\neq}$ & 29.62 & 63 \\
\hline \multirow{2}{*}{$\mathrm{OH}^{-}+\mathrm{CH}_{3} \mathrm{~F} \rightarrow \mathrm{HOCH}_{3}+\mathrm{F}^{-}$} & $V_{f}^{\neq}$ & -2.78 & this work \\
\hline & $\mathrm{V}_{\mathrm{r}}^{\neq}$ & 17.33 & this work \\
\hline \multirow{2}{*}{$\mathrm{OH}^{-} \cdots \mathrm{CH}_{3} \mathrm{~F} \rightarrow \mathrm{HOCH}_{3} \cdots \mathrm{F}^{-}$} & $V_{f}^{\neq}$ & 10.96 & this work \\
\hline & $\mathrm{V}_{\mathrm{r}}^{\neq}$ & 47.20 & this work \\
\hline \multicolumn{4}{|c|}{ Unimolecular and Association Reactions } \\
\hline \multirow[t]{2}{*}{$\mathrm{H}+\mathrm{N}_{2} \rightarrow \mathrm{HN}_{2}$} & $V_{f}^{\neq}$ & 14.69 & this work \\
\hline & $V_{r}^{\neq}$ & 10.72 & this work \\
\hline \multirow[t]{2}{*}{$\mathrm{H}+\mathrm{CO} \rightarrow \mathrm{HCO}$} & $\mathrm{V}_{\mathrm{f}}^{\neq}$ & 3.17 & this work \\
\hline & $V_{r}^{*}$ & 22.68 & this work \\
\hline \multirow[t]{2}{*}{$\mathrm{H}+\mathrm{C}_{2} \mathrm{H}_{4} \rightarrow \mathrm{CH}_{3} \mathrm{CH}_{2}$} & $V_{f}^{f}$ & 1.72 & 68 \\
\hline & $\mathrm{V}_{\mathrm{r}}^{\neq}$ & 41.75 & 68 , this work \\
\hline \multirow[t]{2}{*}{$\mathrm{CH}_{3}+\mathrm{C}_{2} \mathrm{H}_{4} \rightarrow \mathrm{CH}_{3} \mathrm{CH}_{2} \mathrm{CH}_{2}$} & $V_{\mathrm{f}}^{\neq}$ & 6.85 & this work \\
\hline & $\mathrm{V}_{\mathrm{r}}^{\neq}$ & 32.97 & this work \\
\hline \multirow{2}{*}{$\mathrm{HCN} \rightarrow \mathrm{HNC}$} & $V_{f}^{\neq}$ & 48.16 & this work \\
\hline & $V_{r}^{*}$ & 33.11 & this work \\
\hline
\end{tabular}

${ }^{a} \mathrm{~V}_{\mathrm{f}}{ }^{\neq}$denotes forward $\mathrm{BH}$, and $\mathrm{V}_{\mathrm{r}}{ }^{\neq}$denotes reverse $\mathrm{BH}$. 
TABLE 3: Summary of the DFT Methods Tested

\begin{tabular}{|c|c|c|c|c|c|}
\hline method & $X^{\mathrm{a}}$ & year & type & exchange $^{b} /$ correlation $^{c}$ functional & refs \\
\hline LSDA & 0 & 1981 & pure & $\begin{array}{l}\text { Slater's local } \\
\text { Perdew-Wang local }\end{array}$ & 9,70 \\
\hline BP86 & 0 & 1988 & pure & $\begin{array}{l}\text { Becke88 } \\
\text { Perdew's } 1986 \text { GGA }\end{array}$ & 4,5 \\
\hline BLYP & 0 & 1988 & pure & $\begin{array}{l}\text { Becke } 88 \\
\text { Lee-Yang-Parr }\end{array}$ & 5,6 \\
\hline BHandHLYP & 50 & 1993 & HDFT & $\begin{array}{l}\text { Becke } 88 \\
\text { Lee-Yang-Parr }\end{array}$ & $5,6,10$ \\
\hline B3LYP & 20 & 1994 & HDFT & $\begin{array}{l}\text { Becke88 } \\
\text { Lee-Yang-Parr }\end{array}$ & $5,6,12$ \\
\hline BB95 & 0 & 1996 & MDFT & $\begin{array}{l}\text { Becke } 88 \\
\text { Becke95 }\end{array}$ & 5,13 \\
\hline B1B95 & 25 & 1996 & HMDFT & $\begin{array}{l}\text { Becke88 } \\
\text { Becke95 }\end{array}$ & 5,13 \\
\hline PBE & 0 & 1996 & pure & $\begin{array}{l}\text { PBE } \\
\text { PBE }\end{array}$ & 14 \\
\hline PBE1PBE & 25 & 1996 & HDFT & $\begin{array}{l}\text { PBE } \\
\text { PBE }\end{array}$ & 14 \\
\hline mPWPW91 & 0 & 1998 & pure & $\begin{array}{l}\text { modified Perdew-Wang } \\
\text { Perdew-Wang91 }\end{array}$ & 8,19 \\
\hline mPW1PW91 & 25 & 1998 & HDFT & $\begin{array}{l}\text { modified Perdew-Wang } \\
\text { Perdew-Wang91 }\end{array}$ & 8,19 \\
\hline mPWLYP & 0 & 1998 & pure & $\begin{array}{l}\text { modified Perdew-Wang } \\
\text { Lee-Yang-Parr }\end{array}$ & 6,19 \\
\hline VSXC & 0 & 1998 & MDFT & $\begin{array}{l}\text { VSXC } \\
\text { VSXC }\end{array}$ & 21 \\
\hline B97-1 & 21 & 1998 & HDFT & $\begin{array}{l}\text { B97-1 } \\
\text { B97-1 }\end{array}$ & 22 \\
\hline B98 & 21.98 & 1998 & HDFT & $\begin{array}{l}\text { B98 } \\
\text { B98 }\end{array}$ & 20 \\
\hline MPW1K & 42.8 & 2000 & HDFT & $\begin{array}{l}\text { modified Perdew-Wang } \\
\text { Perdew-Wang91 }\end{array}$ & 19,24 \\
\hline B97-2 & 21 & 2001 & HDFT & $\begin{array}{l}\text { B97-2 } \\
\text { B97-2 }\end{array}$ & 22 \\
\hline O3LYP & 11.61 & 2001 & HDFT & $\begin{array}{l}\text { OPTX } \\
\text { Lee-Yang-Parr }\end{array}$ & 32,33 \\
\hline TPSS & 0 & 2003 & MDFT & $\begin{array}{l}\text { TPSS } \\
\text { TPSS }\end{array}$ & 46,48 \\
\hline TPSSh & 10 & 2003 & HMDFT & $\begin{array}{l}\text { TPSS } \\
\text { TPSS }\end{array}$ & 46,48 \\
\hline TPSSKCIS & 0 & 2004 & MDFT & $\begin{array}{l}\text { TPSS } \\
\text { KCIS }\end{array}$ & $24,25,40,46,48$ \\
\hline mPWKCIS & 0 & 2004 & MDFT & $\begin{array}{l}\text { modified Perdew-Wang } \\
\text { KCIS }\end{array}$ & $13,24,25,40$ \\
\hline X3LYP & 21.8 & 2004 & HDFT & $\begin{array}{l}\text { Becke } 88+\text { PW91 } \\
\text { Lee-Yang-Parr }\end{array}$ & $5,6,8,49$ \\
\hline $\mathrm{BB} 1 \mathrm{~K}$ & 42 & 2004 & HMDFT & $\begin{array}{l}\text { Becke } 88 \\
\text { Becke95 }\end{array}$ & $5,13,50$ \\
\hline MPW1B95 & 31 & 2004 & HMDFT & $\begin{array}{l}\text { modified Perdew-Wang } \\
\text { Becke } 95\end{array}$ & $13,19,53$ \\
\hline MPWB1K & 44 & 2004 & HMDFT & $\begin{array}{l}\text { modified Perdew-Wang } \\
\text { Becke } 95\end{array}$ & $13,19,53$ \\
\hline TPSS1KCIS & 13 & 2004 & HMDFT & $\begin{array}{l}\text { TPSS exchange } \\
\text { KCIS }\end{array}$ & $24,25,40,46,48,59$ \\
\hline MPW1KCIS & 15 & 2004 & HMDFT & $\begin{array}{l}\text { modified Perdew-Wang } \\
\text { KCIS }\end{array}$ & $13,24,25,40$, this work \\
\hline MPWKCIS1K & 41 & 2004 & HMDFT & $\begin{array}{l}\text { modified Perdew-Wang } \\
\text { KCIS }\end{array}$ & $13,24,25,40$, this work \\
\hline
\end{tabular}

BHs of HT reactions, and it is a subset of the previous BH42/ 04 database. The HTBH38/04 database is listed in the Supporting Information.

2.4. AE6 and Kinetics9 Benchmark Databases. We parametrized two new hybrid meta DFT methods, namely, MPW1KCIS and MPWKCIS1K (see Table 3), against the AE6 and Kinetics9 benchmark databases. AE6 ${ }^{69}$ is a database of atomization energies for six molecules. Kinetics9 is a database of three forward $\mathrm{BHs}$, three reverse $\mathrm{BHs}$, and three energies of reaction for the three reactions in the BH6 database. ${ }^{69}$ We have previously used this training set to optimize the BB1K method. ${ }^{50}$ The AE6 and Kinetics9 databases are listed in the Supporting Information.
The MPW1KCIS and MPWKCIS1K methods differ only in the value of $X$, which is the fraction of Hartree-Fock exchange. In MPW1KCIS, $X$ is optimized to minimize the root-meansquare error (RMSE) for the AE6 database. In the MPWKCIS1K model, $X$ was adjusted to minimize the RMSE for the Kinetics 9 database. The optimized $X$ parameters for the MPW1KCIS and MPWKCIS1K methods are given in Table 3.

2.5. Theoretical Methods Tested. We tested a number of DFT-type methods against the new database. In particular, we assessed 11 pure DFT or meta DFT methods: LSDA, ${ }^{9,70}$ BP86, ${ }^{4,5}$ BLYP, 56 BB95, ${ }^{13}$ mPWLYP,,${ }^{6,19}$ mPWKCIS, $, 19,24,25,40,46,48$ mPWPW91, ${ }^{19}$ TPSS,${ }^{46,48}$ TPSSKCIS, ${ }^{24,25,40,46,48}$ and VSXC. ${ }^{21}$ We tested 10 hybrid DFT methods: B3LYP, ${ }^{6,11,12}$ B97-1, ${ }^{22}$ 
B97-2, ${ }^{35}$ B98, ${ }^{20}$ BHandHLYP, 10 mPW1PW91, ${ }^{19}$ MPW1K, ${ }^{30}$ O3LYP,${ }^{32,33}$ PBE1PBE, ${ }^{14}$ and X3LYP, ${ }^{49}$ and we also assessed 8 hybrid meta DFT methods: B1B95, ${ }^{13} \mathrm{BB} 1 \mathrm{~K},{ }^{50} \mathrm{MPW} 1 \mathrm{~B} 95,{ }^{53}$ MPWB1K, ${ }^{53}$ MPW1KCIS, MPWKCIS1K, TPSS1KCIS, ${ }^{24,25,40,46,48,59}$ and TPSSh. ${ }^{46,48}$ All these DFT methods are summarized in Table 3.

Note that MPW1KCIS, MPWKCIS1K, TPSS1KCIS, and TPSSh are not the standard keywords of Gaussian03; the keywords required in Gaussian03 to carry out the MPW1KCIS calculation are:

\#MPWKCIS IOp(3/76 = 0850001500)

The keywords required in Gaussian03 to carry out the MPWKCIS1K calculation are:

\#MPWKCIS IOp(3/76 = 0590004100)

The keywords required in Gaussian03 to carry out the TPSS1KCIS calculation are:

\#TPSSKCIS IOp(3/76 = 0870001300)

The keywords required in Gaussian 03 to carry out the TPSSh calculation are:

\#TPSSTPSS IOp(3/76 = 0900001000)

We also tested six ab initio WFT methods. They are the HF, MP $2,{ }^{71} \mathrm{MP} 3,{ }^{72} \mathrm{MP} 4 S D Q,{ }^{72}$ QCISD,${ }^{60}$ and QCISD(T) ${ }^{60}$ methods.
2.6. Geometries, Basis Sets, and Spin-Orbit Energy. All W1 and DFT calculations were carried out using the GaussianO3 ${ }^{73}$ and MOLPRO ${ }^{74}$ programs. Geometries for all molecules in this paper are optimized at the QCISD/MG3 level, where QCISD is quadratic configuration interaction with single and double excitations, ${ }^{60}$ and MG3 is the modified ${ }^{75,76}$ G3Large ${ }^{77}$ basis set. It is also called the G3LargeMP2 ${ }^{76}$ basis set, which is the same as $6-311++\mathrm{G}(3 \mathrm{~d} 2 \mathrm{f}, 2 \mathrm{df}, 2 \mathrm{p})^{78}$ for $\mathrm{H}-\mathrm{Si}$, but improved ${ }^{77}$ for $\mathrm{P}-\mathrm{Ar}$. The $6-311++\mathrm{G}(3 \mathrm{~d} 2 \mathrm{f}, 2 \mathrm{df}, 2 \mathrm{p})$ basis set uses a single- $\zeta$ core and triple- $\zeta$ valence representation with additional diffuse functions on all atoms. The notation "( $3 \mathrm{~d} 2 \mathrm{f}, 2 \mathrm{df}, 2 \mathrm{p})$ " indicates three sets of $\mathrm{d}$ functions and two sets of $\mathrm{f}$ functions for secondrow atoms, two sets of $\mathrm{d}$ functions and one set of $\mathrm{f}$ functions for first-row atoms, and two sets of $\mathrm{p}$ functions for hydrogen. The QCISD/MG3 geometries for molecules and saddle points in this paper can be obtained from the Truhlar group database website. ${ }^{79}$ We tested all DFT methods in Table 3 with a recommended augmented polarized triple- $\zeta$ set, MG3S. The MG3S basis ${ }^{42}$ is the same as MG3 except it omits diffuse functions on hydrogens.

In all of the calculations presented in this paper, the spinorbit stabilization energy was added to all atoms and to selected open-shell molecules, as described previously. ${ }^{75}$

TABLE 4: Mean Errors (kcal/mol) for the NHTBH38/04 Database ${ }^{a, b}$

\begin{tabular}{|c|c|c|c|c|c|c|c|c|}
\hline \multirow[b]{2}{*}{ methods } & \multicolumn{2}{|c|}{$\begin{array}{c}\text { heavy } \\
\text { atom-transfer (12) }\end{array}$} & \multicolumn{2}{|c|}{$\mathrm{NS}^{\mathrm{c}}(16)$} & \multicolumn{2}{|c|}{$\begin{array}{l}\text { unimolecular and } \\
\text { association (10) }\end{array}$} & \multicolumn{2}{|c|}{ total (38) } \\
\hline & MSE & MUE & MSE & MUE & MSE & MUE & MSE & MUE \\
\hline \multicolumn{9}{|c|}{ Pure DFT or Meta DFT } \\
\hline VSXC & -7.44 & 7.44 & -5.30 & 5.30 & -0.91 & 2.40 & -4.26 & 4.67 \\
\hline BB95 & -13.88 & 13.88 & -6.36 & 6.36 & -3.22 & 3.40 & -7.42 & 7.47 \\
\hline mPWKCIS & -13.65 & 13.65 & -6.66 & 6.66 & -2.67 & 3.07 & -7.39 & 7.50 \\
\hline TPSSKCIS & -13.37 & 13.37 & -7.64 & 7.64 & -2.56 & 2.98 & -7.70 & 7.82 \\
\hline mPWPW91 & -14.10 & 14.10 & -7.45 & 7.45 & -2.67 & 3.10 & -7.90 & 8.02 \\
\hline PBE & -14.93 & 14.93 & -6.97 & 6.97 & -2.94 & 3.35 & -8.00 & 8.11 \\
\hline BP86 & -15.51 & 15.51 & -6.91 & 6.91 & -3.41 & 3.87 & -8.32 & 8.45 \\
\hline TPSS & -14.65 & 14.65 & -7.75 & 7.75 & -3.84 & 4.04 & -8.56 & 8.62 \\
\hline BLYP & -14.66 & 14.66 & -8.40 & 8.40 & -3.38 & 3.51 & -8.65 & 8.69 \\
\hline mPWLYP & -15.76 & 15.76 & -8.14 & 8.14 & -3.64 & 3.79 & -8.90 & 8.95 \\
\hline LSDA & -23.48 & 23.48 & -8.50 & 8.50 & -5.17 & 5.90 & -11.84 & 12.05 \\
\hline \multicolumn{9}{|c|}{ Hybrid DFT } \\
\hline MPW1K & -0.83 & 1.89 & 1.12 & 1.28 & 0.96 & 2.42 & 0.48 & 1.78 \\
\hline B97-2 & -3.13 & 3.52 & -1.43 & 1.47 & 0.62 & 1.91 & -1.13 & 1.98 \\
\hline BHandHLYP & 0.07 & 3.04 & 0.95 & 1.39 & 0.76 & 1.98 & 0.61 & 2.04 \\
\hline mPW1PW91 & -5.99 & 5.99 & -1.81 & 1.94 & -0.38 & 2.00 & -2.57 & 3.08 \\
\hline B98 & -5.18 & 5.18 & -2.96 & 2.96 & -0.31 & 1.97 & -2.66 & 3.12 \\
\hline B97-1 & -5.18 & 5.18 & -3.21 & 3.21 & -0.23 & 1.83 & -2.70 & 3.15 \\
\hline PBE1PBE & -6.62 & 6.62 & -1.87 & 2.05 & -0.58 & 2.16 & -2.84 & 3.36 \\
\hline X3LYP & -8.48 & 8.48 & -2.89 & 2.90 & -1.43 & 2.06 & -4.01 & 4.19 \\
\hline B3LYP & -8.49 & 8.49 & -3.25 & 3.25 & -1.42 & 2.02 & -4.17 & 4.34 \\
\hline O3LYP & -8.27 & 8.27 & 2.61 & 4.42 & -1.02 & 2.27 & -1.46 & 4.94 \\
\hline \multicolumn{9}{|c|}{ Hybrid Meta DFT } \\
\hline $\mathrm{BB} 1 \mathrm{~K}$ & -0.69 & 1.58 & 1.23 & 1.30 & 0.53 & 1.44 & 0.50 & 1.40 \\
\hline MPWB1K & -0.77 & 1.69 & 1.08 & 1.19 & 0.52 & 1.61 & 0.41 & 1.43 \\
\hline MPWKCIS1K & -0.77 & 1.97 & 0.92 & 1.17 & 0.91 & 2.05 & 0.43 & 1.66 \\
\hline B1B95 & -4.73 & 4.73 & -0.95 & 1.08 & -0.58 & 1.21 & -1.86 & 2.09 \\
\hline MPW1B95 & -4.62 & 4.62 & -0.81 & 1.21 & -0.52 & 1.31 & -1.75 & 2.14 \\
\hline MPW1KCIS & -8.64 & 8.64 & -3.55 & 3.55 & -1.21 & 1.96 & -4.26 & 4.46 \\
\hline TPSS1KCIS & -9.26 & 9.26 & -4.88 & 4.88 & -1.39 & 2.12 & -5.06 & 5.26 \\
\hline TPSSh & -11.51 & 11.51 & -5.78 & 5.78 & -2.94 & 3.23 & -6.60 & 6.68 \\
\hline \multicolumn{9}{|c|}{$\mathrm{Ab}$ initio WFT } \\
\hline QCISD(T) & 1.04 & 1.21 & -0.62 & 1.08 & 0.30 & 0.53 & 0.13 & 0.96 \\
\hline QCISD & 3.43 & 3.43 & 1.26 & 1.32 & 1.04 & 1.08 & 1.78 & 1.82 \\
\hline MP4SDQ & 8.60 & 8.60 & 1.42 & 1.44 & 3.08 & 3.12 & 3.81 & 3.82 \\
\hline MP2 & 11.76 & 11.76 & 0.74 & 0.74 & 4.71 & 5.44 & 4.80 & 5.00 \\
\hline MP3 & 10.59 & 10.59 & 3.62 & 3.62 & 4.14 & 4.14 & 5.63 & 5.63 \\
\hline $\mathrm{HF}$ & 14.86 & 16.87 & 6.67 & 6.67 & 2.70 & 3.82 & 7.91 & 8.90 \\
\hline
\end{tabular}

${ }^{a}$ MUE denotes mean unsigned error. ${ }^{b}$ MSE denotes mean signed error. ${ }^{c}$ NS denotes nucleophilic substitution. 


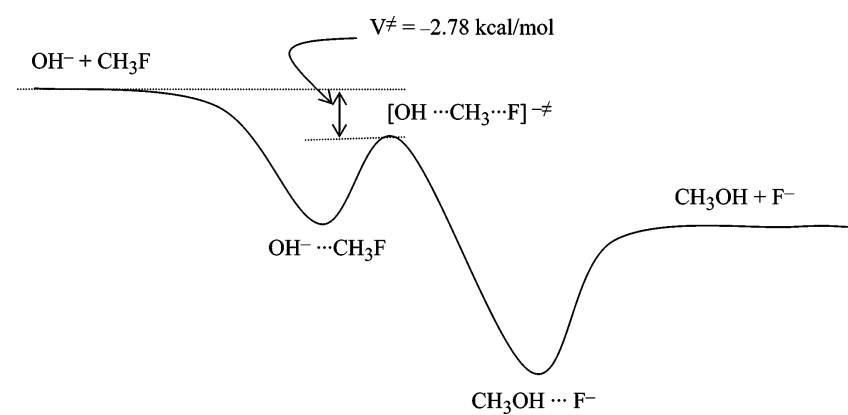

Figure 1. Energy profile along the reaction coordinate for the $\mathrm{OH}-$ $+\mathrm{CH}_{3} \mathrm{~F} \mathrm{~S}_{\mathrm{N}} 2$ reaction. Note that the energy profile includes two wells corresponding to ion-molecule complexes, and the overall forward $\mathrm{BH}$ is negative.

\section{Results and Discussion}

3.1.W1 Results. Table 1 summarizes the $\mathrm{W} 1$ results for the 11 reactions. From this table, it can be seen that the HF calculations overestimate most of the BHs. The CCSD and (T) contributions tend to lower the BHs. The magnitudes of CCSD correlation contributions to the $\mathrm{BHs}$ are in a range from 1 to $32 \mathrm{kcal} / \mathrm{mol}$. The magnitudes of $(\mathrm{T})$ correlation contributions to the $\mathrm{BHs}$ are in a range from 0.5 to $8 \mathrm{kcal} / \mathrm{mol}$. The contributions from core correlation and relativistic effects are much smaller than the CCSD and (T) contribution.

3.2. Benchmark Database of BHs for Non-HT Reactions. The new database is presented in Table 2. We will call this database NHTBH38/04. The magnitudes of the BHs are in the range -13 to $+106 \mathrm{kcal} / \mathrm{mol}$. Four of the $\mathrm{BHs}$ of $\mathrm{S}_{\mathrm{N}} 2$ reactions are negative, which often results from the well-known ${ }^{80,81}$ double-minimum shape of the energy profile (see Figure 1) for many $\mathrm{S}_{\mathrm{N}} 2$ reactions. These overall negative $\mathrm{BHs}$ are well documented in the theoretical ${ }^{63,67,82-85}$ and experimental ${ }^{80,81,86-89}$ studies. There are $12 \mathrm{BHs}$ for heavy-atom transfer reactions, $16 \mathrm{BHs}$ for nucleophilic substitution (NS) reactions, and $10 \mathrm{BHs}$ for non-NS unimolecular and association reaction.

3.3. Test of Theoretical Methods. The mean errors for the new database by the tested methods are listed in Table 4.

Table 4 shows that all 11 pure DFT and meta DFT methods systematically underestimate the BHs. Among these four methods, VSXC gives (by far) the best performance for calculating the BHs for non-HT reactions. This result is consistent with our analysis in a previous paper, ${ }^{90}$ in which we concluded on the basis of a less diverse database that VSXC is the best pure or meta DFT method for thermochemistry and thermochemical kinetics.

TABLE 5: Mean Errors (kcal/mol) for the NHTBH38/04 and HTBH38/04 Databases

\begin{tabular}{|c|c|c|c|c|c|c|c|c|}
\hline \multirow[b]{2}{*}{ methods } & \multicolumn{2}{|c|}{ non-HT (38) } & \multicolumn{2}{|c|}{ HT (38) } & \multicolumn{2}{|c|}{ total $^{a}(76)$} & \multicolumn{2}{|c|}{ weighted average } \\
\hline & MSE & MUE & MSE & MUE & MSE & MUE & MSE & MUE \\
\hline \multicolumn{9}{|c|}{ Pure DFT or Meta DFT } \\
\hline VSXC & -4.26 & 4.67 & -4.86 & 4.87 & -4.56 & 4.77 & -4.63 & 5.00 \\
\hline mPWKCIS & -7.39 & 7.50 & -7.47 & 7.47 & -7.43 & 7.49 & -7.61 & 7.71 \\
\hline TPSSKCIS & -7.70 & 7.82 & -7.01 & 7.01 & -7.36 & 7.42 & -7.65 & 7.75 \\
\hline BB95 & -7.42 & 7.47 & -8.14 & 8.14 & -7.78 & 7.80 & -7.90 & 7.94 \\
\hline mPWPW91 & -7.90 & 8.02 & -8.43 & 8.43 & -8.17 & 8.23 & -8.16 & 8.27 \\
\hline BLYP & -8.65 & 8.69 & -7.52 & 7.52 & -8.09 & 8.11 & -8.49 & 8.52 \\
\hline TPSS & -8.56 & 8.62 & -7.71 & 7.71 & -8.14 & 8.17 & -8.49 & 8.54 \\
\hline PBE & -8.00 & 8.11 & -9.32 & 9.32 & -8.66 & 8.71 & -8.54 & 8.64 \\
\hline BP86 & -8.32 & 8.45 & -9.16 & 9.16 & -8.74 & 8.81 & -8.75 & 8.86 \\
\hline mPWLYP & -8.90 & 8.95 & -8.56 & 8.56 & -8.73 & 8.75 & -9.03 & 9.06 \\
\hline LSDA & -11.84 & 12.05 & -17.72 & 17.72 & -14.78 & 14.88 & -13.72 & 13.90 \\
\hline \multicolumn{9}{|c|}{ Hybrid DFT } \\
\hline MPW1K & 0.48 & 1.78 & -0.60 & 1.32 & -0.06 & 1.55 & 0.16 & 1.73 \\
\hline BHandHLYP & 0.61 & 2.04 & 0.95 & 2.73 & 0.78 & 2.38 & 0.68 & 2.28 \\
\hline B97-2 & -1.13 & 1.98 & -3.09 & 3.24 & -2.11 & 2.61 & -1.76 & 2.54 \\
\hline mPW1PW91 & -2.57 & 3.08 & -3.54 & 3.55 & -3.06 & 3.32 & -2.93 & 3.37 \\
\hline B98 & -2.66 & 3.12 & -4.16 & 4.16 & -3.41 & 3.64 & -3.15 & 3.57 \\
\hline B97-1 & -2.70 & 3.15 & -4.40 & 4.40 & -3.55 & 3.77 & -3.25 & 3.65 \\
\hline PBE1PBE & -2.84 & 3.36 & -4.22 & 4.22 & -3.53 & 3.79 & -3.33 & 3.76 \\
\hline X3LYP & -4.01 & 4.19 & -3.98 & 4.09 & -3.99 & 4.14 & -4.19 & 4.38 \\
\hline B3LYP & -4.17 & 4.34 & -4.13 & 4.23 & -4.15 & 4.28 & -4.32 & 4.50 \\
\hline O3LYP & -1.46 & 4.94 & -3.97 & 4.06 & -2.72 & 4.50 & -2.66 & 4.76 \\
\hline \multicolumn{9}{|c|}{ Hybrid Meta DFT } \\
\hline $\mathrm{BB} 1 \mathrm{~K}$ & 0.50 & 1.40 & -0.57 & 1.16 & -0.03 & 1.28 & 0.13 & 1.37 \\
\hline MPWB1K & 0.41 & 1.43 & -0.85 & 1.29 & -0.22 & 1.36 & 0.00 & 1.45 \\
\hline MPWKCIS1K & 0.43 & 1.66 & 0.14 & 1.71 & 0.29 & 1.69 & 0.30 & 1.73 \\
\hline B1B95 & -1.86 & 2.09 & -2.80 & 2.80 & -2.33 & 2.45 & -2.27 & 2.45 \\
\hline MPW1B95 & -1.75 & 2.14 & -3.02 & 3.02 & -2.38 & 2.58 & -2.24 & 2.54 \\
\hline MPW1KCIS & -4.26 & 4.46 & -4.39 & 4.41 & -4.32 & 4.44 & -4.45 & 4.64 \\
\hline TPSS1KCIS & -5.06 & 5.26 & -4.69 & 4.69 & -4.87 & 4.97 & -5.06 & 5.24 \\
\hline TPSSh & -6.60 & 6.68 & -5.97 & 5.97 & -6.28 & 6.32 & -6.55 & 6.62 \\
\hline \multicolumn{9}{|c|}{ Ab initio WFT } \\
\hline QCISD(T) & 0.13 & 0.96 & 1.15 & 1.24 & 0.64 & 1.10 & 0.47 & 1.02 \\
\hline QCISD & 1.78 & 1.82 & 2.73 & 2.81 & 2.25 & 2.31 & 2.11 & 2.16 \\
\hline MP4SDQ & 3.81 & 3.82 & 3.89 & 3.89 & 3.85 & 3.86 & 4.25 & 4.26 \\
\hline MP2 & 4.80 & 5.00 & 3.69 & 4.14 & 4.24 & 4.57 & 5.23 & 5.52 \\
\hline MP3 & 5.63 & 5.63 & 4.44 & 4.44 & 5.04 & 5.04 & 5.70 & 5.70 \\
\hline $\mathrm{HF}$ & 7.91 & 8.90 & 13.29 & 13.66 & 10.60 & 11.28 & 9.38 & 10.25 \\
\hline
\end{tabular}

${ }^{a}$ This is calculated by using $1 / 4$ times MSE (or MUE) for heavy-atom transfer reaction BHs plus $1 / 4$ times MSE (or MUE) for $\mathrm{S}_{\mathrm{N}} 2$ reaction BHs plus $1 / 4$ times MSE (or MUE) for unimolecular and association reaction BHs plus $1 / 4$ times MSE (or MUE) for HT reaction BHs. 
Among the tested hybrid DFT methods, MPW1K gives the best performance for calculating the heavy-atom transfer reaction $\mathrm{BHs}$ and the $\mathrm{S}_{\mathrm{N}} 2$ reaction $\mathrm{BHs}$. B97-1 gives the lowest mean unsigned error (MUE) for the unimolecular and association reaction BHs. MPW1K is the best hybrid DFT method overall, and it gives the lowest MUE for all $38 \mathrm{BHs}$ in the new database, with B97-2 only slightly behind.

Among the tested hybrid meta DFT methods, BB1K give the best performance for calculating the heavy-atom transfer reaction BHs. B1B95 gives the lowest MUE for the nucleophilic substitution reaction $\mathrm{BHs}$ and the unimolecular and association reaction BHs. BB1K and MPWB1K are the two best hybrid meta DFT methods in that they give lowest MUE for all 38 $\mathrm{BHs}$ in the new database.

Among the tested ab initio WFT methods, QCISD(T) gives the best performance for calculating the non-HT reaction $\mathrm{BHs}$. HF, MP2, MP3, and MP4SDQ systematically overestimate the $\mathrm{BHs}$ as shown by their high mean signed error (MSE). Note that QCISD is outperformed by the BB1K, MPWB1K, MPWKCIS1K, and MPW1K methods even though it is much more computationally expensive.

We also calculated the BHs for the HTBH38/04 database for HT reaction BHs for all DFT methods included in this paper. The results for the HTBH38/04 database and for the new database are compared in Table 5. The quality of a DFT-type method for calculating HT reaction BHs is found to correlate well with its quality for calculating non-HT reaction BHs.

Table 5 also gives the overall mean errors for the combined 76 BHs. To check whether our conclusions are a strong function of the number of each kind of reaction, we also computed weighted mean errors in which each of the four kinds of reaction is weighted by $1 / 4$. Table 5 shows that the conclusions from the weighted mean errors are exactly the same as from the overall mean errors. These conclusions are given in Section 4.

3.4. Analytical Remarks. Although the purpose of this paper is to provide tests, and possibly validations, of density functionals against carefully prepared benchmark data on reactions and not to analyze the functionals theoretically, it is useful to add a few comments on theoretical analysis. The theoretical grounds for admixing Hartree-Fock exchange with GGAs were provided by Becke. ${ }^{11}$ In brief, the GGAs work better for shortrange electron correlation holes, and Hartree-Fock exchange works better for long-range ones. The reason the optimum fraction of Hartree-Fock exchange is less than one-half has been discussed by Perdew et al. ${ }^{15}$ In addition, the density functional exchange builds in effects that are commonly called static correlation in WFT. ${ }^{7,18}$ As a result of these considerations, the optimum amount of Hartree-Fock exchange depends on the molecule or reaction, depends on the property of interest for that molecule or reaction, and, since different GGAs are designed for different purposes, or at least in different ways, also depends on the choice of GGA. For example, some density functionals, such as B1B95, PBE1PBE, TPSS, and TPSSh, build in the exact uniform density limit, ${ }^{13,14,48}$ whereas others do not, and meta density functionals can eliminate the incorrect attribution of electron correlation effects to one-electron regions. The former property is probably more important in metals than in the BHs considered here, whereas the latter is clearly more important in organic chemistry, with its plethora of hydrogen atoms, than in metals. Tables 3 and 5 show that more than about $40 \%$ of HF exchange is needed for hybrid meta DFT or hybrid DFT methods to obtain accurate BHs, as exemplified by the good performance of the BB1K, MPWB1K, MPWKCIS1K, and MPW1K methods. Note that two DFT methods based on nonempirical functionals, namely, TPSS1KCIS and TPSSh, do poorly for $\mathrm{BH}$ calculations because the percentage of $\mathrm{HF}$ exchange in the canonical versions of both methods is small (13 and $10 \%$, respectively).

\section{Concluding Remarks}

In this paper, we developed a benchmark database of forward and reverse BHs for 19 non-HT reactions. We tested 29 DFT methods and 6 WFT methods against the new database and also against a combined database of 38 HT and 38 non-HT BHs. Among the tested pure DFT and meta DFT methods, VSXC ${ }^{21}$ give the best performance for the calculations of $\mathrm{BHs}$, with a MUE of $4.9 \mathrm{kcal} / \mathrm{mol}$. Among the tested hybrid DFT methods, MPW $1 \mathrm{~K}^{30}$ is the most accurate model for calculations of BHs, with a mean unsigned error of $1.6 \mathrm{kcal} / \mathrm{mol}$. The very popular B3LYP $5,6,12$ method has a MUE of $4.4 \mathrm{kcal} / \mathrm{mol}$ for the same database and systematically underestimates BHs. ${ }^{30}$ Among the tested hybrid meta DFT methods, $\mathrm{BB} 1 \mathrm{~K}^{50}$ and $\mathrm{MPWB} 1 \mathrm{~K}^{53}$ are the two most accurate models for the calculations of BHs, with MUEs of 1.3 and $1.4 \mathrm{kcal} / \mathrm{mol}$, respectively. Some other methods with MUEs below $3.5 \mathrm{kcal} / \mathrm{mol}$ are MPWKCIS1K (1.7 $\mathrm{kcal} / \mathrm{mol}), \mathrm{B} 1 \mathrm{~B} 95^{13}(2.5 \mathrm{kcal} / \mathrm{mol}), \mathrm{MPW} 1 \mathrm{~B} 95^{53}(2.5 \mathrm{kcal} / \mathrm{mol})$, B97-2 ${ }^{35}(2.5 \mathrm{kcal} / \mathrm{mol})$, and mPW1PW91 ${ }^{19}$ (3.4 kcal $\left./ \mathrm{mol}\right)$. When using the results of this paper, the reader must ultimately consider more than just the performance of the methods for BHs. For example, we pointed out previously ${ }^{30}$ that, although BHandHLYP has a reasonably low MUE for BHs, it is far less accurate than methods such as MPW1K and mPW1PW91 for energies of reaction, and for that reason (and others), it cannot be recommended for most applications.

Overall, BB1K and MPWB1K are the two best DFT methods for calculating $\mathrm{BHs}$, whereas $\mathrm{QCISD}(\mathrm{T})$ is the best ab initio WFT method for BH calculations, and QCISD is second best, butQCISD is outperformed by the BB1K, MPWB1K, MPWKCIS1K, and MPW1K methods.

Our databases are now much broader than previous kinetics databases for testing electronic structure theory, and this improves our confidence in the conclusions of the present validation study.

Acknowledgment. We are grateful to Jan M. L. Martin for sending us the perl script for W1 calculations. We are grateful to Axel Becke and John Perdew for sharing helpful thoughts on DFT, both in person and by email. This work was supported in part by the U. S. Department of Energy, Office of Basic Energy Science.

Supporting Information Available: The HTBH38/04 database and the calculated BHs are given in the Supporting Information. This material is available free of charge via the Internet at http://pubs.acs.org.

Note Added after ASAP Publication. This article was published ASAP on 2/09/2005. A text change has been made in Table 3. The correct version was posted on $2 / 21 / 2005$.

\section{References and Notes}

(1) Hohenberg, P.; Kohn, W. Phys. Rev. B 1964, 136, 864.

(2) Kohn, W.; Sham, L. J. Phys. Rev. A 1965, 140, 1133.

(3) Perdew, J. P.; Zunger, A. Phys. Rev. B 1981, 23, 5048.

(4) Perdew, J. P. Phys. Rev. B 1986, 33, 8822.

(5) Becke, A. D. Phys. Rev. A 1988, 38, 3098.

(6) Lee, C.; Yang, W.; Parr, R. G. Phys. Rev. B 1988, 37, 785.

(7) Tschinke, V.; Ziegler, T. A. J. Chem. Phys. 1990, 93, 8051.

(8) Perdew, J. P. In Electronic Structure of Solids '91; Ziesche, P., Eschig, H., Eds.; Akademie Verlag: Berlin, 1991; p 11. 
(9) Perdew, J. P.; Wang, Y. Phys. Rev. B 1992, 45, 13244.

(10) Becke, A. D. J. Chem. Phys. 1993, 98, 1372.

(11) Becke, A. D. J. Chem. Phys. 1993, 98, 5648.

(12) Stephens, P. J.; Devlin, F. J.; Chabalowski, C. F.; Frisch, M. J. J. Phys. Chem. 1994, 98, 11623.

(13) Becke, A. D. J. Chem. Phys. 1996, 104, 1040. 3865 .

(15) Perdew, J. P.; Ernzerhof, M.; Burke, K. J. Chem. Phys. 1996, 105, 9982.

(16) Becke, A. D. J. Chem. Phys. 1997, 107, 8554

(17) Filatov, M.; Thiel, W. Mol. Phys. 1997, 847.

(18) Gritsenko, O. V.; Schipper, P. R. T.; Baerends, E. J. J. Chem. Phys. 1997, 107, 5007.

(19) Adamo, C.; Barone, V. J. Chem. Phys. 1998, 108, 664.

(20) Schmider, H. L.; Becke, A. D. J. Chem. Phys. 1998, 108, 9624.

(21) Voorhis, T. V.; Scuseria, G. E. J. Chem. Phys. 1998, 109, 400.

(22) Hamprecht, F. A.; Cohen, A. J.; Tozer, D. J.; Handy, N. C. J. Chem. Phys. 1998, 109, 6264.

(23) Krieger, J. B.; Chen, J.; Iafrate, G. J. Int. J. Quantum Chem. 1998, $69,255$.

(24) Rey, J.; Savin, A. Int. J. Quantum Chem. 1998, 69, 581.

(25) Krieger, J. B.; Chen, J.; Iafrate, G. J.; Savin, A. In Electron Correlations and Materials Properties; Gonis, A., Kioussis, N., Eds.; Plenum: New York, 1999.

(26) Engel, E.; Dreizler, R. M. J. Comput. Chem. 1999, 20, 31.

(27) Hammer, B.; Hansen, L. B.; Norskov, J. K. Phys. Rev. B 1999, 59 , 7413.

(28) Perdew, J. P.; Kurth, S.; Zupan, A.; Blaha, P. Phys. Rev. Lett 1999, $82,2544$.

(29) Becke, A. D. J. Chem. Phys. 2000, 112, 4020

(30) Lynch, B. J.; Fast, P. L.; Harris, M.; Truhlar, D. G. J. Phys. Chem. A 2000, 104, 4811.

(31) Proynov, E.; Chermette, H.; Salahub, D. R. J. Chem. Phys. 2000 , 113,10013 .

(32) Handy, N. C.; Cohen, A. J. Mol. Phys. 2001, 99, 403

(33) Hoe, W.-M.; Cohen, A. J.; Handy, N. C. Chem. Phys. Lett. 2001, 341,319 .

(34) Lynch, B. J.; Truhlar, D. G. J. Phys. Chem. A 2001, 105, 2936.

(35) Wilson, P. J.; Bradley, T. J.; Tozer, D. J. J. Chem. Phys. 2001 , 115,9233 .

(36) Adamo, C.; Barone, V. J. Chem. Phys. 2002, 116, 5933.

(37) Menconi, G.; Tozer, D. J. Chem. Phys. Lett. 2002, 360, 38.

(38) Boese, A. D.; Handy, N. C. J. Chem. Phys. 2002, 116, 9559

(39) Baker, J.; Pulay, P. J. Chem. Phys. 2002, 117, 1441.

(40) Toulouse, J.; Savin, A.; Adamo, C. J. Chem. Phys. 2002, 117, 10465 .

(41) Coote, M. L.; Wood, G. P. F.; Radom, L. J. Phys. Chem. A 2002 , $106,12124$.

(42) Lynch, B. J.; Zhao, Y.; Truhlar, D. G. J. Phys. Chem. A $\mathbf{2 0 0 3 , ~}$ 107,1384

(43) Karasiev, V. V. J. Chem. Phys. 2003, 118, 8576.

(44) Boese, A. D.; Martin, J. M. L.; Handy, N. C. J. Chem. Phys. 2003, 119,3005

(45) Guner, V.; Khuong, K. S.; Leach, A. G.; Lee, P. S.; Bartberger, M. D.; Houk, K. N. J. Phys. Chem. A 2003, 107, 1445.

(46) Staroverov, V. N.; Scuseria, G. E.; Tao, J.; Perdew, J. P. J. Chem. Phys. 2003, 119, 12129.

(47) Hsu, J. Y. Phys. Rev. Lett 2003, 91, 133001.

(48) Tao, J.; Perdew, J. P.; Staroverov, V. N.; Scuseria, G. E. Phys. Rev. Lett. 2003, 91, 146401. 2673

(49) Xu, X.; Goddard, W. A. Proc. Natl. Acad. Sci. U.S.A. 2004, 101,

(50) Zhao, Y.; Lynch, B. J.; Truhlar, D. G. J. Phys. Chem. A 2004, 108,2715

(51) Gomez-Balderas, R.; Coote, M. L.; Henry, D. J.; Radom, L. J. Phys. Chem. A 2004, 108, 2874.

(52) Li, Q. S.; Xu, X. D.; Zhang, S. Chem. Phys. Lett. 2004, 20

(53) Zhao, Y.; Truhlar, D. G. J. Phys. Chem. 2004, 108, 6908

(54) Andersson, S.; Gruning, M. J. Phys. Chem. A 2004, 108, 7621.

(55) Boese, A. D.; Martin, J. M. L. J. Chem. Phys. 2004, 121, 3405

(56) Kohn, W.; Becke, A. D.; Parr, R. G. J. Phys. Chem. 1996, 100, 12974.

(57) Lynch, B. J.; Truhlar, D. G. J. Phys. Chem. A 2003, 107, 3898.

(58) Zhao, Y.; Lynch, B. J.; Truhlar, D. G. J. Phys. Chem. A 2004 $108,4786$.
(59) Zhao, Y.; Lynch, B. J.; Truhlar, D. G. Phys. Chem. Chem. Phys. 2005, 7, 43.

(60) Pople, J. A.; Head-Gordon, M.; Raghavachari, K. J. Chem. Phys. 1987, 87, 5968

(61) Coote, M. L. J. Phys. Chem. 2004, 108, 3865

(62) Martin, J. M. L.; Oliveira, G. d. J. Chem. Phys. 1999, 111, 1843

(63) Parthiban, S.; de Oliveira, G.; Martin, J. M. L. J. Phys. Chem. A

2001, 105, 895

(64) Martin, J. M. L.; Parthiban, S. In Quantum Mechanical Prediction of Thermochemical Data; Cioslowski, J., Ed.; Kluwer: Drdrecht, 2001.

(65) Parthiban, S.; Martin, J. M. L. J. Chem. Phys. 2001, 114, 6014

(66) Boese, A. D.; Oren, M.; Atasoylu, O.; Martin, J. M. L.; Kállay,

M.; Gauss, J. J. Chem. Phys. 2004, 120, 4129.

(67) Tucker, S. C.; Truhlar, D. G. J. Am. Chem. Soc. 1990, 112, 3338

(68) Villa, J.; Corchado, J. C.; Gonzalez-Lafont, A.; Lluch, J. M.; Truhlar, D. G. J. Phys. Chem. A 1999, 103, 5061.

(69) Lynch, B. J.; Truhlar, D. G. J. Phys. Chem. A 2003, 107, 8996

(70) Slater, J. C. Quantum Theory of Molecular and Solids. Vol. 4: The Self-Consistent Field for Molecular and Solids; McGraw-Hill: New York, 1974.

(71) Møller, C.; Plesset, M. S. Phys. Rev. 1934, 46, 618

(72) Hehre, W. J.; Radom, L.; Schleyer, P. v. R.; Pople, J. A. Ab Initio Molecular Orbital Theory; Wiley: New York, 1986.

(73) Frisch, M. J.; Trucks, G. W.; Schlegel, H. B.; Scuseria, G. E.; Robb, M. A.; Cheeseman, J. R.; Montgomery, J. A.; Jr., T. V.; Kudin, K. N.; Burant, J. C.; Millam, J. M.; Iyengar, S. S.; Tomasi, J.; Barone, V.; Mennucci, B.; Cossi, M.; Scalmani, G.; Rega, N.; Petersson, G. A.; Nakatsuji, H.; Hada, M.; Ehara, M.; Toyota, K.; Fukuda, R.; Hasegawa, J.; Ishida, M.; Nakajima, T.; Honda, Y.; Kitao, O.; Nakai, H.; Klene, M.; Li, X.; Knox, J. E.; Hratchian, H. P.; Cross, J. B.; Adamo, C.; Jaramillo, J.; Gomperts, R.; Stratmann, R. E.; Yazyev, O.; Austin, A. J.; Cammi, R.; Pomelli, C.; Ochterski, J. W.; Ayala, P. Y.; Morokuma, K.; Voth, G. A.; Salvador, P.; Dannenberg, J. J.; Zakrzewski, G.; Dapprich, S.; Daniels, A. D.; Strain, M. C.; Farkas, O.; Malick, D. K.; Rabuck, A. D.; Raghavachari, K.; Foresman, J. B.; Ortiz, J. V.; Cui, Q.; Baboul, A. G.; Clifford, S.; Cioslowski, J.; Stefanov, B. B.; Liu, G.; Liashenko, A.; Piskorz, P.; Komaromi, I.; Martin, R. L.; Fox, D. J.; Keith, T.; Al-Laham, M. A.; Peng, C. Y.; Nanayakkara, A.; Challacombe, M.; Gill, P. M. W.; Johnson, B.; Chen, W.; Wong, M. W.; Gonzalez, C.; Pople, J. A. Gaussian 03, Revision C.01; Gaussian, Inc.: Pittsburgh, PA, 2003.

(74) Werner, H.-J.; Knowles, P. J.; Amos, R. D.; Bernhardsson, A.; Berning, A.; Celani, P.; Cooper, D. L.; Deegan, M. J. O.; Dobbyn, A. J.; Eckert, F.; Hampel, C.; Hetzer, G.; Korona, T.; Lindh, R.; Lloyd, A. W.; McNicholas, S. J.; Manby, F. R.; Meyer, W.; Mura, M. E.; Nicklass, A. Palmieri, P.; Pitzer, R.; Rauhut, G.; Schütz, M.; Schumann, U.; Stoll, H.; Stone, A. J.; Tarroni, R.; Thorsteinsson, T. MOLPRO, 2002.6; University of Birmingham: Birmingham, 2002.

(75) Fast, P. L.; Sanchez, M. L.; Truhlar, D. G. Chem. Phys. Lett. 1999 , 306, 407.

(76) Curtiss, L. A.; Redfern, P. C.; Raghavachari, K.; Rassolov, V.; Pople, J. A. J. Chem. Phys. 1999, 110, 4703.

(77) Curtiss, L. A.; Raghavachari, K.; Redfern, P. C.; Rassolov, V.; Pople, J. A. J. Chem. Phys. 1998, 109, 7764.

(78) Frisch, M. J.; Pople, J. A.; Binkley, J. S. J. Chem. Phys. 1984, 80 3265

(79) Lynch, B. J.; Zhao, Y.; Truhlar, D. G. http://comp.chem.umn.edu/ database.

(80) Farneth, W. E.; Brauman, J. I. J. Am. Chem. Soc. 1976, 98, 7891 4219 .

(82) Pellerite, M. J.; Brauman, J. I. J. Am. Chem. Soc. 1980, 102, 5993.

(83) Hu, W.-P.; Truhlar, D. G. J. Am. Chem. Soc. 1995, 117, 10726.

(84) Gonzales, J. M.; Cox, R. S.; Brown, S. T.; Allen, W. D.; Schaefer, H. F. J. Phys. Chem. A 2001, 105, 11327

(85) Gonzales, J. M.; Pak, C.; Cox, R. S.; Allen, W. D.; Schaefer, H. F.; Csaszar, A. G.; Tarczay, G. Chem.-Eur. J. 2003, 9, 2173.

(86) Chabinyc, M. L.; Craig, S. L.; Regan, C. K.; Brauman, J. I. Science 1998, 279, 1882.

(87) Davico, G. E.; Bierbaum, V. M. J. Am. Chem. Soc. 2000, 122 , 1740.

(88) Viggiano, A. A.; Midey, A. J. J. Phys. Chem. A 2000, 104, 6786.

(89) Angel, L. A.; Garcia, S. P.; Ervin, K. M. J. Am. Chem. Soc. 2002 , 105,4042

(90) Zhao, Y.; Pu, J.; Lynch, B. J.; Truhlar, D. G. Phys. Chem. Chem. Phys. 2004, 6, 673 . 